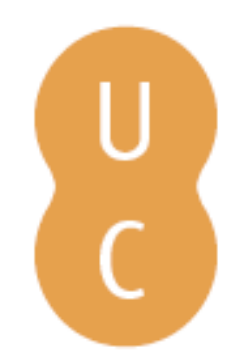

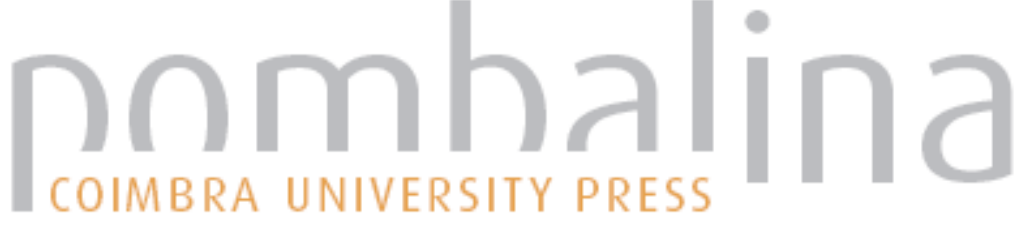

\section{Tomé de Faria, um latinista tradutor epidótico de Os Lusíadas}

\author{
Autor(es): $\quad$ Torres, Amadeu
}

Publicado por: Imprensa da Universidade de Coimbra

URL

persistente: URI:http://hdl.handle.net/10316.2/31211

DOI: $\quad$ DOI:http://dx.doi.org/10.14195/978-989-26-0569-2_37

Accessed : $\quad$ 26-Apr-2023 15:55:31

A navegação consulta e descarregamento dos títulos inseridos nas Bibliotecas Digitais UC Digitalis, UC Pombalina e UC Impactum, pressupõem a aceitação plena e sem reservas dos Termos e Condições de Uso destas Bibliotecas Digitais, disponíveis em https://digitalis.uc.pt/pt-pt/termos.

Conforme exposto nos referidos Termos e Condições de Uso, o descarregamento de títulos de acesso restrito requer uma licença válida de autorização devendo o utilizador aceder ao(s) documento(s) a partir de um endereço de IP da instituição detentora da supramencionada licença.

Ao utilizador é apenas permitido o descarregamento para uso pessoal, pelo que o emprego do(s) título(s) descarregado(s) para outro fim, designadamente comercial, carece de autorização do respetivo autor ou editor da obra.

Na medida em que todas as obras da UC Digitalis se encontram protegidas pelo Código do Direito de Autor e Direitos Conexos e demais legislação aplicável, toda a cópia, parcial ou total, deste documento, nos casos em que é legalmente admitida, deverá conter ou fazer-se acompanhar por este aviso.

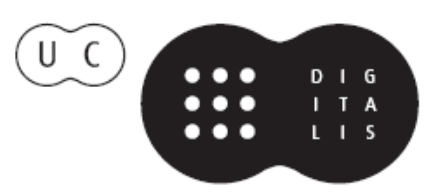




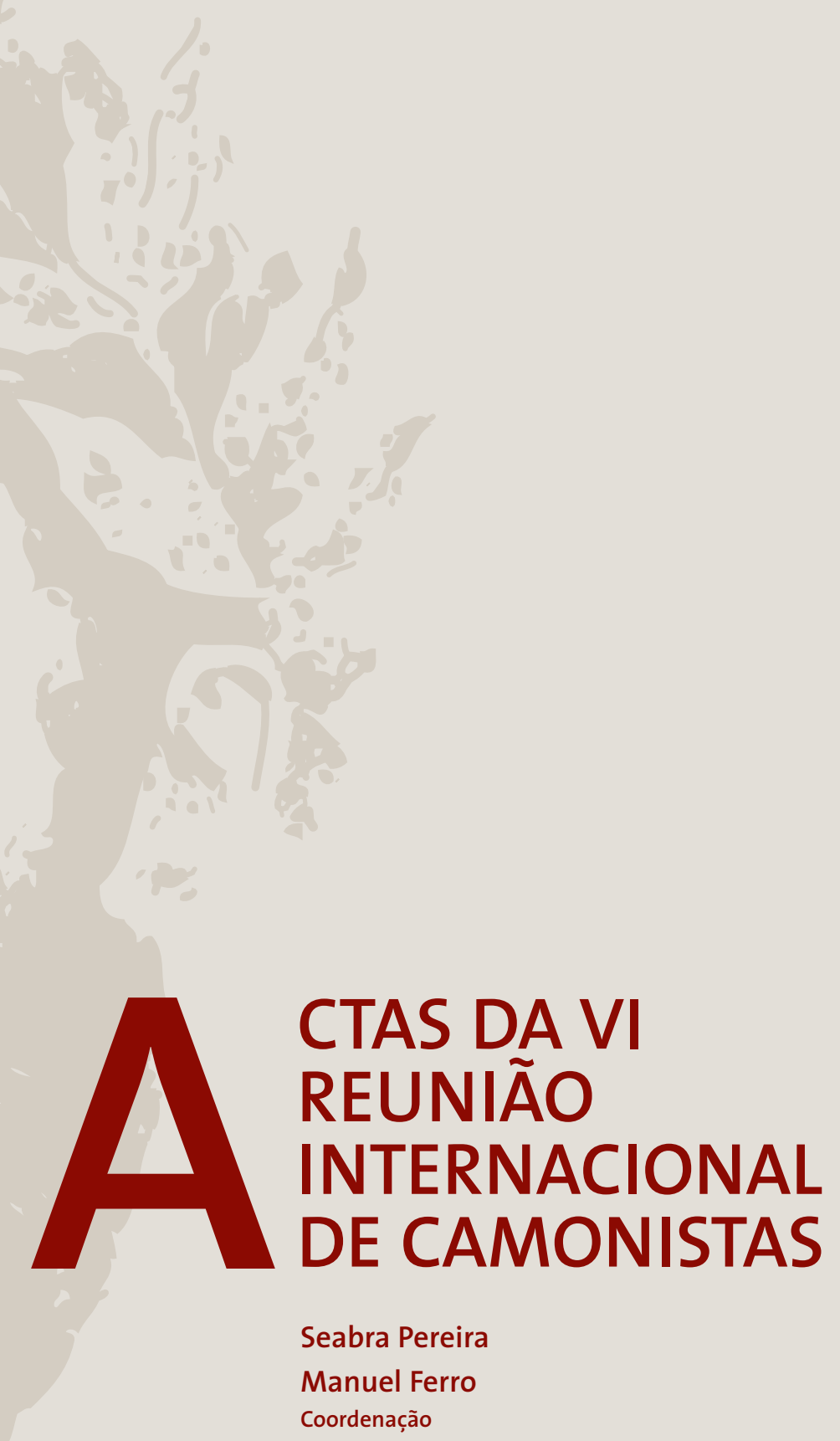




\author{
Amadeu Torres \\ Universidade Católica Portuguesa / Universidade do Minho
}

\title{
TOMÉ DE FARIA, UM LATINISTA TRADUTOR EPIDÓTICO DE OS LUSÍADAS
}

1.- Foi na Biblioteca Nacional, em Paris, que há uns bons trinta anos um feliz acaso na consulta dos ficheiros me colocou perante a edição princeps, revista por António José Viale, de $A$ Lusiada de Luis de Camóes ${ }^{1}$, versão latina de Frei Francisco de Santo Agostinho Macedo (1596-1681), exímio conhecedor da língua do Lácio. O facto de Viale haver substituído as oitavas com que Macedo descreve a Ilha dos Amores por outras da própria lavra, em virtude de achar imperfeitas aquelas, levou-me a analisar a questão em pormenor, a qual culminou com o restituir das mesmas à sua pureza, após a correcção de pequenos senóes, e o verificar finalmente, e sem menos apreço para António José Viale, que em certo sentido "a emenda era pior que o soneto». Estava lançada a semente que iria prender-me repetidamente a atenção, dois ou três lustros depois.

As oportunidades trouxeram-nas os encontros camonianos na capital francesa (1980) sob o patrocínio da Fundação Gulbenkian, na Universidade dos Açores em Ponta Delgada (1983) e na Universidade de São Paulo (1987). Para o colóquio de Paris acerca de Camóes e a civilização do Renascimento colacionei "A Ilha dos Amores d'Os Lusíadas na versão de cinco poetas neolatinos" ${ }^{2}$, destacando-se, como eu já palpitava, Frei Francisco de Santo Agostinho Macedo na companhia de André Baiâo, Tomé de Faria, António José Viale e Francisco de Paula Santa Clara; na reuniáo internacional da Ilha de S. Miguel, acareou-se o mesmo grupo em face do episódio de Inês de Castro ${ }^{3}$, ganhando as palmas outra vez a versão macédica; na assembleia paulista ${ }^{4}$ tratou-se da próxima edição crítica

\footnotetext{
${ }^{1}$ Cf. A Lusiada de Luiz de Camóes, traduzida em versos latinos por Frei Francisco de Santo Agostinho Macedo. Primeira ediçáo, revista por António José Viale, do conselho de Sua Magestade, publicada por Venancio Deslandes. Lisboa, Imprensa Nacional, 1880 (in - 8º., XVII + 478 pp.).

${ }^{2}$ Amadeu Torres, "A Ilha dos Amores d'Os Lusíadas na versão de cinco poetas neolatinos. Uma restituição que se impóe”, Arquivos do Centro Cultural Português, vol. XVI, Paris, Fundação Calouste Gulbenkian, 1981, pp. 201-241.

3 Cf. id., "André Baião, tradutor latino de Os Lusíadas: da diáfrase à hipocléptica semântica", Actas da IV Reuniâo Internacional de Camonistas, Ponta Delgada, 1984, pp. 659-706.

${ }^{4}$ Cf. id., "Para a edição crítica do manuscrito baiânico de Os Lusíadas», Actas da V Reunião Internacional de Camonistas, Univ. de São Paulo, Fac. de Filosofia, Letras e Ciências Humanas, 1987, pp. 517-529; trabalho também publicado, sob a epígrafe de "O Mss. baiânico de Os Lusíadas e a sua próxima edição crítica",
} 
do manuscrito de André Baiāo5, intitulado Ludouici Camoenii Lusitani Libri X, em preparação e fazendo parte de uma futura tese doutoral que estou orientando.

As conclusóes a que em duas das três abordagens recordadas se chegou a respeito de Tomé de Faria e André Baião, quanto ao gradiente de perfeição e fidelidade alcançado por cada um deles como tradutores latinos integrais do Poema nacional, resumemse em dois termos: hipocléptica ou supressão de palavras e conceitos, epidótica ou acrescento, técnicas metodológicas adoptadas respectivamente por Baião e por Faria. Esta VI reunião internacional de Camonistas propicia entretanto, na sequência das anteriores, novo ensejo de confronto dos dados já em posse, seja para confirmá-los ou infirmá-los, seja para introduzir qualquer modificação e ajustamento.

Nesse intuito, escolheram-se as quatro estrofes iniciais dos Cantos I e V de Os Lusíadas, nas versóes de D. Frei Tomé de Faria (1622), carmelita lisboeta (1558-1628) doutorado em Teologia por Coimbra e bispo de Targa, e Frei André Baião (1625), goês com estudos teológicos na Universidade Coimbrã e fama de gramático latino em colégios de Roma, onde jaz (1566-1639). Procedeu-se à separaçáo dos textos em estrofes de acordo com o sentido porque nenhum dos dois, ao contrário de Frei Francisco de Santo Agostinho Macedo (1596-1681), se votou à tarefa de as pôr em evidência. Aos excertos latinos acrescenta-se a sua tradução bastante à letra, para mais rápida aquilatação do labor e aproximação de cada um ao original camoniano, que se insere em rodapé.

2.- Canto I e estrofes iniciais

2.1.- Tomé de Faria

"Arma virosque cano, nostro qui e littore quondam

Occiduo, rapidis soluentes carbasa ventis

Intrepidi, variis et tempestatibus acti

Sulcarunt tumidi metuendas aequoris undas

Littoraque antiquis nunquam bene cognita nautis,

Altaque Taprobanae tetigerunt littora terrae

Et proprio celsis turritas moenibus urbes

Sanguine fundarunt, quarum super aethere famam

Inclyta portantes Christi vexilla tulerunt.

Dulciaque Eois posuere cubilia mundi

Partibus, ignotos traxere in vincula reges,

Et noua regna suis decorarunt legibus, altas

Regibus inuitis, quas nunquam experta patenti

Est natura sinu defendere viribus arces

Non timuere, omni charae discrimine vitae

Posthabito, forti posuerunt fraena Malachae.

em Miscelânea de Estudos em honra do Prof. Américo da Costa Ramalho, Univ. de Coimbra, INIC/Centro de Estudos Clássicos e Humanísticos, 1992, pp. 455-467.

${ }^{5}$ Cf. Ludouici Camoenii Libri X. Ex materno rhythmico in Latinum et Virgilianum Carmen a D. Andrea Baiano Lusiada Orientali traducti, et ab eodem manuscripti Anno Iubilei MDCXXV (in -8º., 383 pp.). 
Lusiadumque etiam nostris memoranda Camaenis Regum facta canam, quantum mea Musa iuuabit, Ingenium dederitque suo de numine Foebus:

Talia carminibus totum celebranda per orbem Heroum spargam, qui forti pectore et armis Imperii metas Lusi, stabilitaque sedis

Romanae mandata (Deo ducente) suamque

Dilatare fidem per tanta pericula vitae.

Haud dubii claros celebrarunt Christe triumphos:

Africa tantorum experta es proelia Regum,

Nam campos urbesque tuas et moenia diris

Vastarunt animis, Asiae fera littora classes

Conspexere, cadunt turres, iuga dura coloni

Accipiunt, nostri percussi vulnere ferri.

Quorum terribilis nec mors, nec tempus iniquum

Delebunt, magnumue ferent ad Tartara nomen.

Conticeant varii cursus sapientis Vlyssis, Aeneae accipiant aeterna silentia ponto Diuersi errores, quos miro carmine Musa Virgiliana canit, sileat fama incyta Magni Regis Alexandri, sileat nova gloria clari Traiani, coluit quos prima decentius aetas. Nam mihi fert animus vires et fortia nostro Pectora Lusiadum versu celebrare, tridenti Quos Neptune tuo, tuque o Mars horride saeuis Atque Erebi veneranda cohors, horrescitis armis. Nec iam Parnassi celeberrima Musa suorum Facta canat, cytharasque suas exaltet Apollo, Lusiadum quando maior se gloria tollit Maior et astrifero se fama exaequat Olympo.

Vos etiam Tagides Nymphae, mea numina, caeptis Aspirate meis, si vestri pectus amoris Ignibus ardet adhuc, si vestro flamine mentem Spiritus intus agit, si vestri fluminis undas Extulit in caelum tenui mea tibia cantu, Et cecinit vestrae viridantia gramina ripae. Nunc nunc caelesti perfundite nectare pectus, Atque iter inceptum flatu properate sereno, Nunc mihi forte pedem, vatemque implete furore: Reddite nunc facili currentia carmina filo, Grandiloquumque sonum, nunc cingite tempora lauro, Phoebus ut efficiat quod non Tagus aurifer, undis Fontis Hypocrene inuideat, sed semper amoenis Fluctibus ipse riget sinuato tramite ripas." 


\subsection{1.- Versão de cunho literal}

Canto as armas e os varôes ${ }^{6}$ que, um dia, da nossa praia ocidental, soltando intrépidos os panos aos ventos rápidos e flagelados por tempestades várias, sulcaram orgulhosos as temíveis ondas do oceano e os litorais desconhecidos por antigos navegantes, atingiram as antigas costas da Taprobana e, à custa do próprio sangue, fundaram cidades rodeadas de torres e altas muralhas cuja fama, com os estandartes insignes de Cristo, se espalhou nos ares. Criaram acolhedores povoados nas regióes do Oriente, trouxeram prisioneiros reis ignotos, proveram de leis novos reinos, não recearam de monarcas inimigos velhas fortalezas que nunca a natureza tentou corajosamente defender a peito descoberto; e, desprezando todos os perigos da preciosa vida, impuseram freios à poderosa Malaca.

Cantarei também os feitos dos reis de Portugal, dignos de serem exaltados pelas nossas Camenas, tanto quanto a minha Musa me ajudar e Febo em sua benevolência me outorgar engenho: espalharei em verso, pelo orbe inteiro, as façanhas memoráveis dos heróis que, de peito esforçado e armas na máo, através de tamanhos riscos da vida, dilataram (com o auxílio divino) as fronteiras do Império Luso, bem como a doutrina própria da Igreja Romana e a sua Fé. Sem dúvida que alcançaram, ó Cristo, triunfos brilhantes: tu, África, experimentaste lutas de bem grandes reis, ao serem desvastados os teus campos e cidades e muralhas por ânimos assanhados; e as armadas alcançaram os litorais selvagens da Ásia: desabam as torres, os indígenas recebem a dura servidão feridos da nossa espada. O seu nome nem a morte horrenda nem o tempo iníquo destruirão, ou então hão de levá-lo até ao Tártaro.

\footnotetext{
${ }^{6}$ Cf. Com as oitavas correspondentes de Os Lusiadas (de harmonia com a edição príncipe, na reprodução da INCM, de 1983, actualizada, quanto possível):

"As armas e os varôes assinalados

Que da Ocidental praia Lusitana,

Por mares nunca de antes navegados

Passaram ainda além da Taprobana,

Em perigos e guerras esforçados,

Mais do que prometia a força humana,

E entre gente remota edificaram

Novo reino que tanto sublimaram.

E também as memórias gloriosas

Daqueles reis que foram dilatando

A Fé, o Império, e as terras viciosas

De África e de Ásia andaram devastando;

$\mathrm{E}$ aqueles que por obras valerosas

Se vão da lei da morte libertando:

Cantando espalharei por toda a parte,

Se a tanto me ajudar o engenho e arte.

Cessem do sábio Grego e do Troiano

As navegaçóes grande que fizeram;

Cale-se de Alexandre e de Trajano

A fama das vitórias que tiveram;

Que eu canto o peito ilustre Lusitano

A quem Neptuno e Marte obedeceram.

Cesse tudo o que a Musa antiga canta,

Que outro valor mais alto se alevanta."
} 
Calem-se as navegaçôes várias do sapiente Ulisses, e no oceano guardem eterno silêncio os errores muitos de Eneias, que a Musa virgiliana canta em maravilhoso poema; silencie-se a fama ínclita do rei Alexandre Magno e bem assim a glória nova de Trajano ilustre, aos quais a Idade Antiga prestou honras. Na verdade, impulsa-me o espírito a celebrar, em verso nosso, o valor do esforçado peito lusitano contra quem tu, Neptuno com o teu tridente, e tu, Marte, terrivelmente vos enfureceis; e vós, veneranda corte do Érebo, atacais de armas em riste. Não cante já a musa celebérrima do Parnaso as gestas dos seus, nem alteie Apolo as suas cítaras, porque glória maior dos Lusos se alevanta e maior fama ascende ao astrífero Olimpo.

E vós, Ninfas do Tejo, minhas protectoras, auxiliai os meus intentos, se o coração vos arde ainda no fogo do vosso amor, se o espírito move dentro a mente com a vossa inspiração, se a minha frauta exaltou até aos céus, em ténue canto, as águas do vosso rio e celebrou os prados verdejantes das vossas margens. Mas agora inundai de néctar celeste o meu peito e apressai, com um sopro sereno, o caminho encetado; agora porventura, enchei de ardor os pés do vate; agora tornai correntes os versos, num fluir suave, e grandíloquo o som; agora coroai-me a cabeça de louro, para que Febo faça com que o Tejo aurífero náo inveje as àguas da Fonte de Hipocrene, antes sempre irrigue, em sinuoso curso, de amenas águas as suas margens.

\section{2.- André Baião}

"Arma virosque cano, Luso qui solis ab orbe Occidui per non aliis freta peruia nautis Taprobanen venere super mortalia praeter Ausa diu multum terris pelagique per undas Iactati, multa et bello discrimina passi, Et longinqua nouum posuerunt littora regnum Quod prope diuinis illustrauere triumphis.

Nec minus illorum studia immortalia regum Qui Christi late imperiis crescentibus almam Protendere fidem, Lybiae Asiaeque profanos Diripuere locos, quos et praestantibus ausis Mors vel tempus edax rerum non exedere.

Errores Ithaci Teucrique per aequora cessent; Cedant, Magne, tui cedant, Traiane, triumphi, Dum Lusitanum iubar excito, Mars quibus ipse Seruiit, ipse quoque et Neptunus paruit ultro. Musa vetus sileat, quia maior in orbe terrarum Surgit honos, maior rerum praescribitur ordo.

Vos Tagides Nymphae, unde mihi nouus inditus ardor Ingenii mecum teneris adoleuit $\mathrm{ab}$ annis, Carmine si tenui laeto tamen aurea semper Flumina vestra dedi patriis resonare Camoenis, 
Aspirate mihi: date carmina digna cothurmo, Carmina Maeonio, Tagicas ut Delius undas

Pegaseis faciat nihil inuidisse fluentis."

\subsection{1.-Versão nos moldes da anterior}

Canto as armas e os varóes que do mundo Luso, a Ocidente, por mares desconhecidos de outros nautas, chegaram, através de feitos mais que humanos, além da Taprobana; grandemente e por longo tempo debatendo-se por terras e oceanos, não só arrostaram com inúmeros perigos, como outrossim levantaram nos litorais longínquos um novo reino que ilustraram de triunfos quase divinos.

E não menos as empresas imortais daqueles reis que largamente estenderam a Fé vivificadora de Cristo a novos impérios, conquistaram regióes pagãs da África e da Ásia, e cujos ilustrados empreendimentos nem a morte nem o tempo devorador das coisas farão perecer.

Cessem as navegaçôes do Grego e do Troiano; calem-se, Magno e Trajano, os vossos triunfos, enquanto eu exalto a glória dos Lusos a quem o próprio Marte serviu e outrossim o mesmo Neptuno espontaneamente obedeceu. Guarde silêncio a antiga Musa, porque uma honra maior surge no Mundo, uma ordem superior das coisas se estabelece.

Vós, Ninfas do Tejo, donde inspirado ardor de engenho cresceu comigo desde tenros anos, se em verso humilde mas alegre sempre fiz por louvar, com pátrio ritmo, as vossas águas doiradas, inspirai-me: dai-me um canto digno da perfeição Meónia, a fim de que Délio faça com que as águas do Tejo em nada invejem a Fonte de Pégaso.

3.- Canto V, nas quatro primeiras estrofes

3.1.- Tomé de Faria

"Talia dicta senex profert, nova carbasa ventis

Tradimus et placida vecti contendimus aura, Et de more polum soluentes vela ferimus

Vocibus; extemplo ventus deducere naves

Incoepit, duro spumas salis aere ruebant.

Tempus erat quo Sol fulgenti luce Leonem

Feruidus intrabat sextaque aetate vigebat

Mundus, at infirmus cursu rerumque labore,

Mille quater centum iam tunc compleuerat annos

Et nonaginta septem perfecerat orbes;

In quo versatur cursu Sol aureus, alas

Cum classis placidis soluebat in aequore ventis.

Iam procul apparent paulatim et littora, montes,

Culmina, iam rupes oculus non cernit amoenas;

Cynthia pulchra manet campis et rupibus altis,

Linquitur auriferis Tagus amnis fluctibus, arua

Quae rigat in patria, lassataque protinus urbe

Corda manent lacrymis maestis fletuque referta. 
Et postquam tellus nostris euanuit alma

Luminibus, undique maria, undique et undique caelum.

Caeruleas tumidi sic findimus aequoris undas,

Gentibus ignotas mundi conspeximus oras

Littoraque ac terras quas illustrissimus alto

Henricus regno adiunxit montesque superbos

Et Lybiae rupes quas gens Maurusia tractu

Colligit ipsa suo, fecundam quam impius olim

Antheus incoluit terram camposque patentes,

Atque hanc laeua tenet, teneat quam dextera nautis

Est satis incertum quamquam suspecta feratur."

3.1.1.-Versão ao nível já indicado

Tais palavras ${ }^{7}$ profere o anciáo [quando] apontámos os panos novos aos ventos, nos entregámos ao sopro da aragem plácida e o céu ferimos, como de costume, aos

\footnotetext{
7 Cf. Do Canto V de Os Lusiadas, as quatro primeiras estrofes:

"Estas sentenças tais o velho honrado

Vociferando estava, quando abrimos

As asas ao sereno e sossegado

Vento, e do porto amado nos partimos.

E como é já no mar costume usado,

A vela desfraldando, o céu ferimos,

Dizendo «Boa viagem!». Logo o vento

Nos tronos fez o usado movimento.

Entrava neste tempo o eterno lume

No animal Nemeio truculento;

E o Mundo, que co tempo se consume,

Na sexta idade andava, enfermo e lento.

Nela vê, como tinha por costume,

Cursos do Sol catorze vento cento,

Com mais noventa e sete, em que corria,

Quando no mar a armada se estendia

Já a vista pouco a pouco se desterra

Daqueles pátrios montes, que ficavam;

Ficava o caro Tejo e a fresca serra

De Sintra, e nela os olhos se alongavam.

Ficava-nos também na amada terra

O coraçẫo, que as mágoas lá deixavam.

E já depois que toda se escondeu,

Não vimos mais, enfim, que mar e céu.

Assim fomos abrindo aqueles mares,

Que geração alguma não abriu,

As novas ilhas vendo e os novos ares

Que o generoso Henrique descobriu;

De Mauritânia os montes e os lugares,

Terra que Anteu num tempo possuiu,

Deixando à mâo esquerda, que à direita

Não há certeza doutra, mas suspeita.”
} 
gritos desdobrando as velas: logo o vento começou a conduzir as naus, sulcando o duro bronze a salsa espuma.

Era o tempo em que o Sol, de luz fulgente, entrava férvido no Leão, e o mundo, adoentado da vida e do trabalho, andava na sexta idade, então já de mil e quatrocentos anos volvidos, mais noventa e sete rotaçôes completas. Encontrava-se o Sol áureo neste signo, quando a frota no mar abria as asas aos ventos plácidos.

Já, ao longe, aparecem pouco a pouco as praias, os montes, as cumeadas; já a vista não discerne as agradáveis penedias. Fica-nos a bela Cíntia de campos e altos rochedos, deixase o rio Tejo de auríferas águas e as searas que ele irriga, e logo os coraçôes lassos se ficam na cidade banhados de tristes lágrimas e pranto. E depois que a terra amada se escondeu aos nossos olhos, por todo o lado o mar, por todo o lado e todo o lado o céu.

Orgulhosos, assim sulcamos as cerúleas águas do oceano, vimos costas desconhecidas dos povos, litorais e terras que o ilustríssimo Henrique acrescentou ao velho Reino, e as montanhas soberbas e penhascos da Líbia que o povo Mouro em seu território contém, terra que outrora o ímpio Anteu tornou fecunda, assim como as extensas planícies. Esta situa-se à nossa esquerda; à direita ignoram os marinheiros que terra esteja, embora haja suspeita.

\section{2.- André Baião}

"Talia iactabat senior cum mollibus alas

Pandimus ingenteis zephyris charoque soluti

Prouehimur portu; interea naualis uti res

Exigit, extensis clamamus ad aethera velis,

"Salve" omneis clamore via cursuque precanteis.

Protinus incubuit, concusso robore, ventus.

In Nemeae immortale feram iubar ibat, et orbis

Iam tum canescens, sextaque aetate laborans,

Mille supra, centumque quater nouiesque videbat

Dena, quibus septem quoque iunge volumina solis,

Cum medium classis tenuit mare.

Jam loca sensus

Diffugiunt patriae. Vagrusque Tagusque recedunt

Maesta ubi corda manent oculisque sequentibus haerent.

Postquam omnis latuit tractus, nec iam amplius ulla

Apparet tellus, caelum undique et undique pontus.

Sic aliis nondum notum rude findimus aequor,

Henrici crebris legimus freta consita terris,

Laeva relinquenteis Maurum iuga et oppida quondam

Anthaeus quae ingens tenuit, nam dextera quaenam

Sit plaga vix certum est."

\subsection{1.- Versão em iguais moldes}

Tais palavras lançava o ancião quando abrimos as asas aos largos zéfiros serenos e, âncoras levantadas, nos partimos do amado porto. Entretanto, como é hábito no mar, 
desfraldadas as velas às auras, alçámos todos o brado do adeus pela viagem e partida. Logo o vento soprou com força e movimento.

Caminhava o lume imortal para a fera de Nemeia, e o mundo, já então encanecido e enfermo, na sexta idade se via de quatrocentos e nove vezes dez além de mil, acrescentadas mais sete revoluçóes solares, quando a armada se adentrou no oceano.

Já os sentidos se alongam dos lugares pátrios. Afastam-se Sintra e o Tejo, onde ficam os coraçóes saudosos e se prendem os olhos lá cravados. Depois que toda esta parte se escondeu e mais terra alguma aparece, em toda a volta o céu e em toda a volta o mar.

Assim sulcámos o bravo oceano, dos outros ainda ignorado, e rumámos pelos estreitos, povoados das terras de Henrique, deixando à esquerda as montanhas dos Mouros e as cidades que outrora o gigante Anteu possuiu, que à direita não há certeza sobre que terra existirá.

4.- Diz-se que Picasso, quando pintava um quadro, concebia a partir dele seis ou sete variaçóes, de modo a satisfazer melhor qualquer visitante interessado e implicativo. Aqui a oferta é apenas de duas e a escolha recairá, proventura sem grandes perplexidades, na de André Baiáo, em virtude de reflectir maior proximidade do modelo. A variação de Tomé de Faria, essa recorda-me, não obstante o abuso semântico a que a sujeito, certa frase de Rilke, que qualifica a poesia como uma "investigação espiritual". De facto, manipulou de tal forma as estrofes citadas do Canto I, em vez de reproduzir os traços originais, que o seu trabalho sabe a pesquisa barroca patriótico-espiritual de dados dispensáveis, porque quase todos pleonásticos em acepção tão-só etimológica ou, também, subjectivamente literária. No Canto $\mathrm{V}$, porém, reprimiu tal "furor" investigativo, substituindo-o por um equilibrado comedimento hermenêutico.

Repare-se, antes de mais, no número de versos com que os tradutores interpretaram as oitavas do Poema:

\begin{tabular}{|c|c|c|c|c|c|}
\hline \multicolumn{3}{|c|}{ CANTO I } & \multicolumn{3}{c|}{ CANTO V } \\
\hline Camóes & Faria & Baião & Camões & Faria & Baiáo \\
\hline 8 & 16 & 7 & 8 & 5 & 6 \\
8 & 16 & 5 & 8 & 7 & 4,5 \\
8 & 13 & 6 & 8 & 8 & 4,5 \\
8 & 14 & 7 & 8 & 9 & 4,5 \\
\hline 32 & 59 & 25 & 32 & 29 & 19,5 \\
\hline
\end{tabular}

Como uma sinopse destas deixará sérias dúvidas aos leitores a respeito do rigor de cada um dos intérpretes no seu labor translativo, acrescenta-se outra, agora de cariz semântico, pois que se apontam, com referência a Os Lusíadas, as correspondências, os acréscimos e as supressóes, quase sempre pormenorizadamente, salvo em Tomé de Faria no Canto I, onde a profusão de sinais toma o lugar de significante privilegiado e suficiente. 


\begin{tabular}{|c|c|c|c|c|c|}
\hline Oitavas & \multicolumn{2}{|c|}{ CANTO I } & Oitavas & \multicolumn{2}{|c|}{ CANTO I } \\
\hline & Faria & Baiáo & & Faria & Baião \\
\hline I & ++ & $=$ & I & $\begin{array}{c}\text { Boa viagem } \\
+ \text { novos } \\
+ \text { sulcando o } \\
\text { duro bronze a } \\
\text { salsa espuma. }\end{array}$ & o céu ferimos \\
\hline II & ++ & $\begin{array}{l}-5^{\circ} \text {. verso e } \\
\text { atribuição de } \\
\text { tudo aos reis }\end{array}$ & II & $\begin{array}{c}\text { - truculento } \\
5^{\circ} . \text { verso } \\
\text { - como tinha por } \\
\text { costume } \\
\text { + férvido } \\
{ }^{+} \text {ventos plácidos }\end{array}$ & $\begin{array}{c}\text { - lento } \\
\text { como tinha } \\
\text { por } \\
\text { costume }\end{array}$ \\
\hline III & ++ & $\begin{array}{l}\text { - sábio } \\
\text { - grandes } \\
\text { - fama }\end{array}$ & . & $\begin{array}{c}\text { - fresca } \\
\text { - caro } \\
+ \text { praias } \\
+{ }^{+} \text {cumeadas } \\
{ }^{+} \text {agradáveis penedias } \\
+{ }^{+} \text {campos } \\
{ }^{+} \text {auríferas águas } \\
{ }^{+} \text {searas que ele irriga }\end{array}$ & \\
\hline IV & ++ & - corrente & IV & $\begin{array}{c}\text { - novos ares } \\
+ \text { orgulhosos } \\
+ \text { cerúleas } \\
{ }^{+} \text {costas } \\
+ \text { litorais } \\
+ \text { velho Reino } \\
+ \text { soberbos } \\
+ \text { que o Mouro em seu } \\
\text { território contém } \\
\text { + extensas planícies }\end{array}$ & $\begin{array}{l}\text { - generoso } \\
\text { - descobriu } \\
\text { - novas } \\
\text { - novos ares } \\
\text { + gigante }\end{array}$ \\
\hline
\end{tabular}

Na linha do que já se previa, os dados sinópticos apurados vêm confirmar as conclusôes das duas abordagens anteriores atrás aludidas. Com efeito, em André Baião a tendência para a sobriedade e contenção não obstaculizou o desamor a pormenores julgados de somenos, mau grado nem sempre se nos afigure que acerta nessa avaliação. A sua atitude pende bastante para a hipocléptica léxico-semântica, sem desatenção ao essencial.

Em Tomé de Faria prevalece o oposto, conquanto o adivinhemos, qual se depreende dos dotes patenteados pela amostragem do Canto V, bem capaz de cometimentos menos redundantes. Todavia, ainda em casos assim, náo consegue escapar ao recurso a pequenos acréscimos, a roçarem por vezes, como no Canto I, a paráfrase. Isto apesar de ser destro e culto no manejo das duas línguas em jogo, a de partida que era o português, a de chegada que era o latim. Longe, portanto, da aventura de Castilho, ao traduzir o Fausto de Goethe com base em sete versões 
abertas à sua roda, três portuguesas e quatro francesas, porque desconhecia o alemão ${ }^{8}$.

É verdade que Almada Negreiros opinava poder a Selva, de Ferreira de Castro, ascender ao nível das obras primas quando traduzida para vernáculo a partir da versão francesa de Blaise Cendrars. Não vou por aí, sem reservas. De facto, se qualquer tradução implica criação, isso não a autoriza a transcender o modelo ou a substituílo por um mesmo-outro sémica ou esteticamente mais louçainhado, na aparência ou na realidade.

Foi o que praticou, afinal, Tomé de Faria, a quem por isso se ajusta apropriadamente, segundo penso, o epíteto de tradutor epidótico de Os Lusíadas.

${ }^{8}$ Cf. Fausto, poema dramático trasladado a português por Castilho, Porto, Civilização Editora, 1938, em "Advertência", p. 11. 